\title{
'I'm not what I used to be': A Qualitative Study Exploring How Young People Experience Being Diagnosed with a Chronic Illness
}

\section{DOI:}

10.1111/cch.12638

\section{Document Version}

Accepted author manuscript

Link to publication record in Manchester Research Explorer

Citation for published version (APA):

Kirk, S., \& Hinton, D. (2019). 'I'm not what I used to be': A Qualitative Study Exploring How Young People Experience Being Diagnosed with a Chronic Illness. Child: Care, Health and Development. https://doi.org/10.1111/cch.12638

Published in:

Child: Care, Health and Development

\section{Citing this paper}

Please note that where the full-text provided on Manchester Research Explorer is the Author Accepted Manuscript or Proof version this may differ from the final Published version. If citing, it is advised that you check and use the publisher's definitive version.

\section{General rights}

Copyright and moral rights for the publications made accessible in the Research Explorer are retained by the authors and/or other copyright owners and it is a condition of accessing publications that users recognise and abide by the legal requirements associated with these rights.

\section{Takedown policy}

If you believe that this document breaches copyright please refer to the University of Manchester's Takedown Procedures [http://man.ac.uk/04Y6Bo] or contact uml.scholarlycommunications@manchester.ac.uk providing relevant details, so we can investigate your claim.

\section{OPEN ACCESS}




\section{'I'm not what I used to be': A Qualitative Study Exploring How Young People Experience Being Diagnosed with a Chronic Illness}

Short Title: Being Diagnosed with a Chronic Illness

Susan Kirk PhD; MSc; BNurs; RN; RM; RHV1.

Professor of Family and Child Health

Denise Hinton PhD; MA; BA.

Research Associate

Keywords: Chronic illness, long-term condition, diagnosis, children, adolescent, qualitative.

${ }^{1}$ School of Health Sciences, University of Manchester, Oxford Road, Manchester M13 9PL, UK. Email: sue.kirk@manchester.ac.uk 


\section{ABSTRACT}

BACKGROUND: Childhood long-term conditions are usually diagnosed in infancy or early childhood. Little is known about the particular experiences and needs of young people who receive a chronic illness diagnosis during adolescence or late childhood. This paper will examine this experience in relation to Multiple Sclerosis (MS) which is increasingly being diagnosed before adulthood.

AIMS: To explore how young people experience an MS diagnosis.

METHODS: Qualitative study using a grounded theory approach. In-depth interviews were conducted with 21 young people diagnosed with MS. Participants were recruited through health service and voluntary sector organisations in the United Kingdom.

FINDINGS: Young people's pre-illness normality was disrupted by the diagnosis of a chronic illness (MS). Participants experienced their body as changed physically, cognitively and emotionally and as changeable due to symptom unpredictability. This influenced how participants perceived and presented their identity, disrupted their relationships and altered their future biography. Young people developed strategies to manage their condition and identities in order to incorporate MS into their current and future lives which required continual illness and identity work in response to changing symptoms, social contexts and relationships.

CONCLUSIONS: While young peoples' experience of living with chronic illness has been widely explored, the aftermath of diagnosis has been under-researched from their perspective. This study contributes to this knowledge gap by illuminating how young people experience a chronic illness diagnosis and negotiate the resulting changes to their identity, relationships and future. The findings suggest that young people need preparation and support in disclosing their diagnosis to others. Professionals supporting young people with long-term conditions need to work closely with specialist mental health services to ensure they receive appropriate emotional support. Schools have an important role in ensuring young people with long-term conditions achieve their academic potential and receive appropriate careers advice. 


\section{INTRODUCTION}

Over recent decades the number of children living with a chronic illness has increased significantly with an estimated $12 \%$ of young people aged $10-19$ years having a long-term health condition (DH 2012; Leeman et al 2016). However, they may experience poorer psycho-social and educational outcomes when compared to their healthy peers (Champaloux and Young, 2015; Lum et al 2017; Nylander et al 2014;). Research exploring young peoples' experiences of living with different conditions has uncovered consistent themes. Studies highlight how living with a chronic illness involves managing physical symptoms such as pain and living a life that is structured and controlled by treatment regimens (Atkin and Ahmed, 2001; Guell, 2007; Heaton et al 2016). The theme of normalization is woven through the literature. Studies describe how young people experience a sense of difference due to treatment regimens, physical limitations and visible differences (Jessup and Parkinson, 2010; Lambert and Keogh, 2015; Taylor et al 2008). However, there is evidence that they strive to see and present themselves as 'normal' (Cartwright et al 2014; Knight et al 2016; Tong et al 2012). The literature identifies different strategies young people use to achieve a sense of normality and peer acceptance. To minimise the disruption of therapeutic regimens and background their illness they may stop or adapt treatments (Curtis-Tyler, 2010; Taylor et al 2008). Young people may reframe their sense of normality by using downward social comparison to define themselves as fortunate as a means of adjusting to a sense of difference (Jamieson et al 2014; Monaghan and Gabe, 2015, 2016). However, the most commonly cited strategy for managing difference appears to be concealment with studies describing how (where possible) young people conceal their illness (Barned et al 2016; Benson et al. 2015; Taylor et al 2008; Venning et al 2008).

While young peoples' experience of living with chronic illness has been widely explored, the aftermath of diagnosis has been under-researched from their perspective. Research about diagnosis has largely focussed on cancer and HIV/AIDS with a particular emphasis on diagnosis disclosure to young people. This highlights the benefits of disclosure in terms of improved psycho-social wellbeing and the pivotal role parents play in determining the timing and nature of information disclosed (Instone, 2000; Wiener et al 2007; Young et al 2003). Chronic illness diagnosis has been conceptualised in relation to biography, in terms of disrupting, disintegrating, reinforcing or continuing an anticipated biography (Bray et al., 2014). However, this concept originates from adult studies and its application to children who have often experienced chronic illness from birth/early childhood has been debated (Bray et al, 2014; Williams, 2000; Williams, 2009). Indeed, studies examining biography in relation to children/young people have highlighted its relevance is more nuanced and related to context and timing (Grinyer, 2007; Monaghan and Gabe 2015; Williams et al 2009). 
This paper focuses on the experiences of young people (under 18 years old) following a chronic illness diagnosis, in this case that of multiple sclerosis (MS). MS is a progressive neurological condition associated with physical and/or cognitive impairments (Banwell et al 2007). While MS is typically diagnosed during adulthood, advances in imaging technologies have recently led to the diagnosis being made during childhood (Absoud et al 2012). Consequently, very little is known about young people's experiences of living with this uncommon and complex childhood condition. Canadian studies about childhood MS have highlighted young people's feelings of loss and grief and the challenges integrating treatment regimens and physical limitations into their daily lives (Boyd and MacMillan, 2005; Thanhausser, 2009; Thanhausser et al 2009). In addition, quantitative studies have discovered that young people with MS report lower health-related quality of life (HRQoL) scores (Mowry et al, 2010) and have suggested that the fatigue they commonly experience may be associated with depression, reduced HRQoL and lower school performance (Carroll et al 2016; Toussaint-Duyster et al 2018). To our knowledge there have been no in-depth qualitative studies conducted about young people's experiences of living with MS outside of Canada. In this paper we also aim to contribute to the wider literature by focussing on how young people respond to a chronic illness diagnosis as little is currently known about how they experience the aftermath of diagnosis.

\section{METHODOLOGY AND METHODS}

The study was guided by constructivist grounded theory principles (Charmaz, 2014). Grounded theory is useful for exploratory research that aims to illuminate subjective experience and develop an indepth understanding of the topic being researched.

\section{Sampling and Recruitment}

Sixteen specialist paediatric MS centres provided all parents with a child aged 8-17 years old with a clinically-confirmed MS diagnosis with study information. Parents were asked to pass on study information to their children. In addition four voluntary organisations advertised the project via their websites, social media accounts and membership magazines. Parents contacted the researchers directly about their child's interest in participation and to arrange an interview. The majority of the sample were female with a mean age of 15 years old (Table 1 ).

\section{Data Collection}

Young people were given the opportunity be interviewed with or without their parents present. Eighteen of the 21 young people chose to be interviewed with their parents present which may have influenced data generation (MacLean and Harden, 2014) (Table 2). Interviews were semi-structured 
and guided by a topic guide (Figure 1). Questioning was directed at the young people. In some interviews the parent's presence appeared to enhance data generation as they clarified events being discussed by their child or provided prompts that facilitated their children's accounts. All interviews were conducted in home settings by the second author, an experienced qualitative researcher. They were digitally recorded and transcribed verbatim. Data collection continued until categories were fully developed.

\section{Data Analysis}

Interview transcripts were analysed inductively using NVIVO. Initial codes were developed from lineby-line coding that examined experiences, actions and assumptions (Charmaz, 2014). Open and focused coding were used to develop categories and understand their relationships. During this process, a core category 'the changed and changeable body' was identified as being central to participants' experiences of living with MS. Authors met regularly to discuss the analysis, data interpretation and code/category development.

\section{Reflexivity}

We tried to maintain a reflexive standpoint throughout the study, examining how we may have influenced the research process and the co-construction of data (Berger, 2015). A reflexive journal was used to record beliefs, actions and observations that might have influenced data generation and analysis. We considered how our positionality (adult, white, middle class, parents) and our professional knowledge (a combination of clinical and non-clinical expertise) may have shaped our interaction with young people and influenced data generation (Figure 2). We were aware that familiar adult-child relationships (parent/child, doctor/patient, teacher/student) typically frame the child as dependent on and deferential to adult authority which could engender a perceived power imbalance.

\section{Ethical Issues}

A National Health Service Research Ethics Committee approved the study. Informed assent/consent was obtained from all young people (and from the parents of those under 16 years) who were provided with detailed age-appropriate information about the study. Procedures were developed to manage participant distress and disclosure. Participants were assured of confidentiality and anonymity. In the data extracts presented the associated names are pseudonyms. 


\section{FINDINGS}

During data analysis the 'changed and changeable body' emerged as the core category in the analysis that explained young peoples' experiences of living with an MS diagnosis and connected three subcategories ('an altered identity', 'changed relationships' and 'a reconfigured future'). 'The changed and changeable body' is the context for changes in identity, relationships and future biography.

\section{A Changed and Changeable Body}

Prior to diagnosis participants described experiencing a gradual onset of bodily changes such as headaches, visual disturbances and balance problems that appeared and disappeared. It was only when these symptoms continued or worsened that they were interpreted as problematic, necessitating a medical consultation. However, this rarely led swiftly to a diagnosis due to professional unfamiliarity with childhood MS and the complexity of diagnosis. Consequently, participants could endure a period of considerable uncertainty. While some participants described positive feelings at being given an MS diagnosis as the label presented the possibility of treatment and symptom relief, others described feelings of shock and distress, because as Durriyah explained, the condition was perceived as affecting the most 'precious' parts of the body:

a teardrop just fell off my eye, and I was like, why did that happen to me? Especially to my brain and spine, that's the most precious part, why did it happen to that?.... I felt sad, upset, depressed and very stressed. I used to cry every night just thinking about it. (Durriyah)

MS was described as having changed various parts of their bodies such as their limbs, eyes, bladders and brains which created difficulties with control over movement, vision and continence. Bodies were now experienced as 'weak', 'tired', 'numb' and often painful. However, participants did not only experience physical changes, many described changes in their cognitive abilities which had led to memory loss and concentration difficulties. These physical and cognitive limitations could disrupt their education and social lives. Consequently, their awareness of their changed body (and lives) was associated with feelings of sadness and depression with some participants volunteering that they had experienced suicidal thoughts:

I just felt so numb and so much in pain, like mentally as well. Like I felt like really, really bad in pain and I had suicidal thoughts because I just thought, I can't do this, I really, really can't do this because it just hurts so much and I'm frustrated at myself, why did I have to get stuff like this. (Louise)

From participants' accounts it was evident that they saw their body as unpredictable and changeable due to symptom variability. The body in effect was continually changing as both new and familiar symptoms appeared and disappeared. Moreover, it was unknown whether these symptoms would disappear, worsen or remain. Emotions similarly varied in response to symptom experience with hope 
being evident during remissions and despair during relapses. However, these fluctuating periods of illness and wellness provided the possibility for participants to have periods when MS moved into the background of their lives:

The only time it shoots me down is when I'm poorly. When I'm not poorly it doesn't bother me at all. It's like it's not there, you just don't think about it do you? You just put it out of your head. (Rebecca)

Controlling the impact of MS on their bodies and preventing relapses involved participants (or their parents) in administering regular injections (daily/weekly) of a disease modifying therapy (DMT). Although they had had to adjust to the pain and anxiety associated with injections, treatment was seen as improving and controlling symptoms which in turn gave participants some sense of control over their bodies. Indeed some participants tried to gain further control of their bodies by adopting healthier life styles such as eating well and exercising. However, the treatments themselves could also be perceived as controlling and constraining their lives:

I was angry because I had all this and had to take all this medication and it just controlled my life. I mean, I used to say all it does is control my life, I can't do anything because of it; can't go here, can't go there. (Nadia)

In addition, DMT and steroid medication could result in distressing physical and behavioural sideeffects that had to be managed which further influenced their ambivalent perception of treatment. Participants described their feelings of distress at the marks on their bodies from injections and the weight gain and mood changes associated with steroids:

I don't like taking them because I don't like the way I become, the anger and the violence and that. I also don't like it because you get fat and you can't stop eating. (Clare)

The changed and changeable body participants experienced appeared to influence how they perceived and presented their identity and redefined their relationships and future biography.

\section{An Altered Identity}

Being diagnosed with MS and experiencing a changed and changeable body appeared to alter participants' sense of their own identity. As Rebecca and Zoe explained they perceived themselves to be different to the person they had been pre-diagnosis:

I got told I had something wrong with me, and that's running through my head. I kind of felt like I'd changed person. (Rebecca)

I'm not what I used to be ... I wrote a status on Facebook, like, I have had a serious diagnosis that will affect my life. .... that was, like, the day I got the diagnosis. (Zoe) 
These perceptions appeared to be a consequence of both the physical and personality changes they associated with MS. Participants described experiencing new emotions and behaviours, such as anger and sadness, that they did not recognise as being part of their previous personality:

I was like I was me, my body was there but my personality wasn't there. (Louise)

Moreover, their illness experience was believed by some participants to have positively changed their personality as they perceived themselves as having become more mature, motivated and compassionate. In addition, the physical changes experienced also altered participants' sense of their identity. For some participants MS had disrupted the physically activity that had been a central part of their pre-illness identity (and social relationships), for example, dancing, cheerleading, football. Attempting to retain physical activity in their lives appeared to be a means of preserving their preillness identity, enabling them to still see themselves as 'active' and 'healthy' and thereby develop and maintain a new sense of personal normalcy.

Alongside developing and adjusting to a changed personal identity, participants' accounts highlighted fears about the potential for MS to disrupt their pre-illness social identity if they were redefined as 'different' by their peers. In order to preserve and protect their social identity participants controlled information about themselves and their condition. As MS may be an invisible condition during periods of remission this presented the possibility of concealing the diagnosis from others, allowing participants to preserve their existing identity. However, identity management by concealment was threatened by the emergence of illness markers from treatment side-effects or physical limitations during relapses which could make MS visible. Indeed, participants appeared to move from concealment to openness over time as they adjusted to the diagnosis and their altered identity.

Most participants had selectively disclosed their diagnosis to close friends, teachers or family members but had been open about their condition if directly questioned by others. They described their reasons for this as the need to provide explanations for school absences or evident illness symptoms:

I don't think there's a need to shout about it and tell everyone, I'm only close to a couple of people in my college class, so I only really told them because it makes them realise stuff, like about why I can't walk very far. I don't know I haven't found a reason to tell other people. (Isla)

Close friends yeah, I'm not bothered, but people, you know, outside don't need to know... it's none of their business is it? (Oscar)

While most participants described disclosing the information about their changed identity in a faceto-face context, one participant had used social media for disclosure in the hope that this would avoid 
having to provide explanations, but which instead had resulted in the receipt of numerous messages asking for further information. Having disclosed their condition, participants described a range of reactions from friends and peers which they then had to manage, which included disbelief due to MS being associated with adulthood, difficulties in comprehending the information and displays of distress. Louise described her own feelings of distress and guilt at her friend's reaction:

My guy friend who's like my brother, he came in and he just burst into tears. And I've never seen him burst into tears like that over me. And it was heart-breaking because I felt mad for making them upset. (Louise)

Explaining about MS could be challenging as peers could find it difficult to comprehend and make sense of the information:

They don't actually know what it means, but they know l've got it. (Nathan)

It's really difficult to tell them anything, and you do give them an answer and they still have no idea what you just said and expect more. But at the same time if you try to go into detail they don't want that because they don't understand it. (Nancy)

Participants' pre-illness personal and social identity appeared to be disrupted by MS and their attempts to create and maintain a non-different identity was compromised by the unpredictability of bodily changes and the variable success of treatments in controlling the body. This altered identity appeared to structure their relationships with others.

\section{Changed Relationships}

Participants' accounts suggested that an MS diagnosis had altered their relationships. They discussed how their relationships with their parents (particularly mothers) had strengthened and become closer due to the time they had spent together during the diagnostic period when they had shared experiences and feelings. Indeed, some participants used the term 'friendship' to describe their changed relationship:

I tell my mum nearly everything, no matter how embarrassing and what a girl really shouldn't tell her mum about, I do tell...about that to my mum. Because my mum is literally my best friend (Louise)

I know I can talk to Dad about stuff, no matter how bad it is (Courtney)

While changes to relationships with siblings appeared to be more varied, the marginalisation of siblings was evident in some accounts, and participants presented them as 'attention-seekers' or 'disinterested' in their condition. 
The MS diagnosis and participants' altered illness identities appeared to shape their relationships with their peers in different ways. Firstly, friendships appeared to be defined to some extent by the provision of practical and emotional support. Friends were reported to help with school work, carried bags, raised spirits, listened, advocated and made allowances for physical limitations. Paradoxically while participants described valuing peer support, at the same time their accounts presented a desire for an MS diagnosis not to lead to their being treated differently.

A MS diagnosis was described by some participants as having disrupted friendship networks with friends being both lost and gained. Some reflected on how friendships had been lost as a result of their friends' lack of understanding, jealousy or loss of contact during periods of illness. As Ella explained, disclosing her diagnosis tested the strength of friendships:

My closest friends were kind of just like, oh, just kind of get on with it.... I think, almost a bit jealous, ... I kind of moved away from them.... I only see really the friends that stuck by me ... I'm really good friends with the one who did actually really stick by me. Whereas my closer friends who didn't, I don't really see them that much anymore. (Ella)

However, new friendships could be formed with other adults and young people with MS, based on a shared illness experience which appeared to reduce their feelings of isolation.

While many participants presented their peers as supportive and understanding, there were descriptions of experiences of bullying (some via social media) that they related to their changed body (such as weight gain, mobility difficulties) which influenced identity formation and caused distress.

I used to get bullied, girls thought that I was some creature or alien from another planet, they used to say that to me and they used to say that I'm not normal, the way I walk, the way I do things (Durriyah)

I used to get really badly, like, bullied over it because of my weight. Like, I used to take steroids, like, a lot of them, they used to say, oh, watch out, Nadia's going to come and punch you with her mega muscles. ... people used to say pretty nasty stuff. .... call me a druggie..... It got really bad because I felt extremely depressed and I used to cry, and I just felt like I wanted to just end it all. I thought to myself, maybe if I ended it all, maybe it'd go away, and nobody'd bother me. (Nadia)

An MS diagnosis appeared to alter and structure their social relationships. While it provided an opportunity to strengthen relationships with parents, it appeared to change peer relationships in a more nuanced way.

\section{The Reconfigured Future}

Although there were two participants who found it difficult to articulate their expectations and hopes for the future, most accounts presented a future which incorporated MS. Participants described developing an understanding that MS would always be part of their lives and part of their future 
It's not a death sentence, it's more a life sentence, it changes your life. So it's with me for the rest of my life, but it's not going to kill me. (Suravi)

They described having to overcome both their own and others vision of the 'MS future', symbolised by a wheelchair, which they associated with limitations and a loss of friends:

When you say MS and when, the first thing that people think, disabled, in a wheelchair, about to die and old. Well, that's not true.... I think the one thing that people think about when you say, oh, I've got MS, and they think, oh my God, wheelchair. (Louise)

If I tell people that I know, they'll all go, you're going to be in a wheelchair. ..... everyone just has an image of it, because she did say, oh but people with MS can't walk. And I was like, well, they can. (Ella)

Most participants rejected this vision and instead portrayed themselves as ambitious with aspirations to succeed in life. Many described having long and short-term future goals in relation to their education, career and travel plans. Indeed, the diagnosis was seen by Zoe to have increased her motivation:

I've actually been more motivated to get the good grades that I know I can, rather than sit and think, oh, I've got MS, I can't do that. It's made me want to more be like I can do that, I've got MS and it's not going to stop me from doing that .... I'm just more motivated to do everything. Like in the weirdest way possible, it's actually done me more good. (Zoe)

Participants described developing a degree of acceptance of their situation alongside a sense of determination to not allow MS to derail their ambitions and goals for the future:

I felt, well people have got worse things than me, so l'll just get on with it. So I just like, got up and shook it off and just got on with it..........You can't let it beat you, can you really?.... If you're just going to lay in bed all day you're not going to accomplish anything are you? (Rebecca)

I want to do so much in life I don't want this to be a barrier .... I want to do lots of volunteering and stuff and lots of education, I don't want any of this sickness or illness in my way. (Durriyah)

While participants described maintaining their previous aspirations and goals, they were aware that they would need to consider the potential for MS to affect these:

I've got plan $A$, and then plan B ....I've got a plan B for that [university], just in case I can't, because of MS.... I think that's the only thing, that I have to consider that I've got MS in every decision I make. (Suravi)

Some participants described how they already adjusted their goals as certain careers (for example, being a dancer, soldier, hairdresser) were no longer seen as possible due to the physical activity involved and alternative plans were developed. Indeed, some participants' explanations for their reconfigured future related to their experiences of school disruption and difficulties catching up with 
work rather than physical/cognitive impairment. In conclusion, while an MS diagnosis prompted the need for participants to reappraise their future, their accounts suggested that they had incorporated MS into their future biography and constructed their futures optimistically.

\section{DISCUSSION}

Many studies have explored young people's experiences of living with a chronic illness but little is known about how they experience the aftermath of diagnosis. This study contributes to knowledge by examining the repercussions of this life-changing event. In this study due to their age at diagnosis participants were able to describe, reflect on and understand the physical, cognitive and emotional changes resulting from MS and the personal and social consequences of diagnosis. There are study limitations. We recognise that participants' accounts and their subsequent analysis may have been influenced by the interviews being conducted and interpreted by adult researchers (Harden et al 2010). Parents' presence in the interviews may have also influenced how participants presented their experiences, for example, their positive relationships with parents (Gardner and Randall, 2012). The findings are based on a self-selected sample. Most participants were female which may mean the experience presented is gendered. While our sample composition could reflect differences in the willingness to participate, MS is known to be more prevalent in females than males (Absoud et al 2012; Hanne et al 2013). Nonetheless, studies suggest gender may influence young people's experiences of chronic illness and identity construction which should considered when considering transferability of findings (Williams, 2000; Williams et al 2009).

Diagnosis was a pivotal moment that legitimised participants' experiences of bodily change and formally labelled their body as altered. Following diagnosis participants described experiencing a changed personal identity and were concerned about being redefined by their peers as 'different'. Consequently, they engaged in actions that aimed to preserve their pre-illness identity. Previous research has similarly highlighted how young people with chronic illness feel different to their peers and strive to present themselves as 'normal' to maintain and reinforce a non-different identity (CurtisTyler, 2010; Benson et al. 2015, 2016; Jessup and Parkinson, 2010; Williams et al 2009). However, how young people feel personally changed by a chronic illness diagnosis has previously been underexplored.

Participants used information control as a strategy for identity management. Concealment of illness has been previously identified (Barned et al 2016; Benson et al 2015, 2016; Kaushansky et al 2017; 
Venning et al 2008;), however, research has highlighted how non-disclosure may exclude young people from peer support and be associated with poor adjustment, distress, social isolation and poor self-image (Gerson et al 2001; Tong et al 2012; Instone 2000). Participants' transition to openness was prompted in part from choice but also by the need to justify and explain school absences and visible symptoms. Managing diagnosis disclosure appeared to be challenging for participants, involving contending with peer distress, bullying and providing convincing explanations for a condition associated with symptom variability and adulthood. This finding suggests that young people need preparation and support in disclosing their diagnosis and managing others' reactions.

Participants' outward appearance of normalcy was continually threatened by unpredictable symptoms and physical changes. As others have highlighted fluctuating periods of illness and wellness challenged participants' identity construction creating difficulties in incorporating illness into their lives (Saunders, 2017; Monaghan and Gabe 2016; Knight et al 2016). Moreover, the identity work undertaken by participants involved reconciling the differences in their self-identities before and after diagnosis and preserving their social identities against a background of 'normal' adolescent identity development. Young people are simultaneously managing the complex developmental tasks associated with adolescence alongside living with a chronic illness (Lambert and Keogh, 2015; Grinyer, 2007). Consequently, diagnosis during adolescence involves incorporating chronic illness into an evolving identity. Indeed, as others contend diagnosis at this life stage appears to be different to diagnosis at birth/early childhood where illness is likely to be already embedded in self-identify (Williams, 2000; Williams et al 2009).

Participants' social relationships were altered and structured by an MS diagnosis. Relationships with parents were strengthened which appeared to relate to their shared 'diagnosis journey'. This contradicts other studies that have presented relationships with parents in terms of conflict and ambivalence (Atkin and Ahmed, 2001; Taylor et al 2008; Christin et al 2015). MS shaped participants' peer relationships in different ways. Peers were presented as providing practical and emotional support which could conflict with participants' desire to be seen as non-different post-diagnosis. Others have noted this tension between the desire to be treated 'normally' and the need for allowances to be made (Pini et al 2016). Diagnosis disclosure could lead to disrupted friendships. Difficulties developing and maintaining friendships due to school absences (despite social media use) have been highlighted previously (Pini et al 2016; Birks et al 2006; Secor-Turner et al 2011; Gabe et al 2002). This is concerning as friendships are important for young people with chronic illnesses (Tong et al 2012; Pendley et al 2002; Jamieson et al 2014). 
In this study participants reappraised and adjusted their envisioned futures to incorporate their diagnosis. Consistent with previous studies, participants appeared to be future orientated, making plans about education, employment and independent living albeit with a degree of uncertainty (Jessup and Parkinson, 2010; Cartwright et al 2014, Donovan et al 2015). When discussing altered educational and career choices, participants perceived this resulting not only from physical and cognitive limitations but also from the educational impact of school absences. Indeed, other studies have associated school absences with poor educational attainment for young people with long-term conditions (Jamieson et al 2014, Lum et al 2017; Pini et al 2012). Consequently, it is important schools develop strategies to help young people manage their school work to achieve their academic potential and provide tailored careers advice.

Study participants reported a complex interplay of feelings post-diagnosis, with some young people reporting having experienced suicidal feelings. Research suggests that young people with long-term conditions are at risk of mental health problems (Pinquart and Shen 2010; Brady et al 2017). This study suggests that young people would benefit from access to post-diagnosis emotional support to discuss the physical, cognitive, psychological and social impact of their diagnosis. This may mean that professionals supporting young people with long-term conditions need training about the emotional impact of diagnosis, identifying mental health problems, providing emotional support and need to work closely with specialist mental health services. 
Key Messages

- A chronic illness diagnosis during adolescence alters how young people experience their body and perceive their identity, relationships and future.

- Young people need preparation and support for diagnosis disclosure and the subsequent reactions (particularly of friends and peers).

- Young people need support in managing their feelings post-diagnosis.

- Professionals supporting young people with long-term conditions may need additional training to provide emotional support and to work closely with specialist mental health services.

- Schools need to develop strategies to help young people with long-term conditions manage their school work so that they can achieve their academic potential and ensure they receive appropriate careers advice. 


\section{REFERENCES}

Absoud, M; Lim, MJ; Chong, WA; De Goede, C; Foster, K et al. (2013) Paediatric acquired demyelinating syndromes: incidence, clinical and magnetic resonance imaging. Multiple Sclerosis Journal 19 (1) 76-86.

Atkin, $\mathrm{K}$ and Ahmed, W (2001) Living a 'normal' life: young people coping with thalassaemia major or sickle cell disorder Social Science \& Medicine 53 615-626

Banwell B, Ghezzi A, Bar-Or A, Mikaeloff Y, Tardieu M. (2007) Multiple sclerosis in children: clinical diagnosis, therapeutic strategies, and future directions. Lancet Neurology. 6(10):887-902

Benson, A; Lambert, V; Gallagher, P; Shahwan, A; Austin, JK. (2015) "I don't want them to look at me and think of my illness, I just want them to look at me and see me": Child perspectives on the challenges associated with disclosing an epilepsy diagnosis to others. Epilepsy \& Behavior 53: 83-91.

Benson, A; O'Toole, S; Lambert, V; Gallagher, P; Shahwan, A; Austin, JK (2016) The stigma experiences and perceptions of families living with epilepsy: Implications for epilepsy-related communication within and external to the family unit. Patient Education and Counseling 99: 1473-1481

Berger R. (2015) Now I see it, now I don't: researcher's position and reflexivity in qualitative research. Qualitative Research 15: 219-234.

Barned, C; Stinzi, A; Mack, D; O’Doherty, KC. (2016) To tell or not to tell: A qualitative interview study on disclosure decisions among children with inflammatory bowel disease Social Science \& Medicine $162115 \mathrm{e} 123$

Boyd JR and MacMillan L. (2005) Experiences of children and adolescents living with multiple sclerosis. Journal of Neuroscience Nursing 37: 334-342.

Brady, AM; Deighton, J; Stansfield, S. (2017) Psychiatric outcomes associated with chronic illness in adolescence: A systematic review. Journal of Adolescence. 59 112-123

Bray, L; Kirk, S and Callery, P. (2014) Developing Biographies: Children, Young People and their Parents' Experiences of Living with a Long-Term Condition. Sociology of Health and IIIness 36(6) 823-839

Birks, Y; Sloper, P; Lewin, R; Parsons, J. (2006) Exploring health-related experiences of children and young people with congenital heart disease Health Expectations, 10,.16-29

Cartwright,T; Fraser,E; Edmunds, S; Wilkinson, N; Jacobs, K (2014) Journeys of adjustment: the experiences of adolescents living with juvenile idiopathic arthritis Child: care, health and development, 41 (5) 734-743

Carroll, S; Chalder, T; Hemingway, C; Heyman, I; Moss-Morris, R (2016) Understanding fatigue in paediatric multiple sclerosis: a systematic review of clinical and psychosocial factors. Developmental Medicine \& Child Neurology 58: 229-239

Champaloux, SW \& Young, DR (2015) Childhood Chronic Health Conditions and Educational Attainment: A Social Ecological Approach. Journal of Adolescent Health 56 98-105 
Christin, A; Akre, C; Berchtold, A and Suris, JC (2015) Parent-adolescent relationship in youths with a chronic condition Child: care, health and development, 42 (1) 36-41

Charmaz K. (2014) Constructing grounded theory. London: Sage. (second edition).

Curtis-Tyler, K (2010) Levers and barriers to patient-centred care with children: findings from a synthesis of studies of the experiences of children living with type 1 diabetes or asthma. Child: care, health and development, 37(4) 540-550

Donovan, E; Brown, L; LeFebvre, L; Tardif, S; Love, B (2015) "The Uncertainty Is What Is Driving Me Crazy": The Tripartite Model of Uncertainty in the Adolescent and Young Adult Cancer Context Health Communication, 30: 702-713.

Department of Health (2012) Long Term Conditions Compendium of Information (Third Edition). London: Department of Health

Gabe, J; Bury, M; Ramsay, R. (2002) Living with asthma: the experiences of young people at home and at school. Social Science \& Medicine 55 1619-1633

Gardner H, Randall D (2012) The effects of the presence or absence of parents on interviews with children. Nurse Researcher. 19 (2) 6-10.

Gerson, AC; Joyner, R; Fosarelli, P. Butz, A. Wissow, L. (2001) Disclosure of HIV Diagnosis to Children: When, Where, Why, and How. Journal of Pediatric Health Care 15 (4) 161-167

Guell, C (2007) Painful Childhood: Children Living With Juvenile Arthritis Qualitative Health Research 17 (7) $884-892$

Grinyer, A (2007) The biographical impact of teenage and adolescent cancer Chronic Illness 3, 265277

Harden, J; Backett-Milburn, K; Hill, M; MacLean, A. (2010) 'Oh, what a tangled web we weave: experiences of doing 'multiple perspectives' research in families', International Journal of Social Research Methodology, 13 (5), $441-452$

Hanne F. Harbo, R; Gold, R; Tintoré, M (2013) Sex and gender issues in multiple sclerosis Therapeutic Advances in Neurological Disorders. 6(4): 237-248.

Heaton, J; Raisanen, U; Salinas, M (2016) 'Rule your condition, don't let it rule you': young adults' sense of mastery in their accounts of growing up with a chronic illness Sociology of Health \& IIIness 38 (1) $3-20$

Instone, SL (2000) Perceptions of Children With HIV Infection When Not Told for So Long: Implications for Diagnosis Disclosure Journal of Pediatric Health Care 14(5):235-43

Jamieson, N; Fitzgerald, D; Singh-Grewal, D; Hanson, CS; Craig, JC; Tong, A. (2014) Children's Experiences of Cystic Fibrosis: A Systematic Review of Qualitative Studies Pediatrics 133:e1683-e1697

Jessup, M and Parkinson, C (2010) "All at Sea": The Experience of Living With Cystic Fibrosis Qualitative Health Research 20(3) 352-364 
Kaushansky,D; Cox, J; Dodson, C; McNeeley,M ; Kumar, S; Iverson, E (2017) Living a secret: Disclosure among adolescents and young adults with chronic illnesses Chronic Illness 13(1) 49-61

Knight , A; Vickery, M; Fiks AG and Barg, FK (2016) The illness experience of youth with lupus/mixed connective tissue disease: a mixed methods analysis of patient and parent perspectives Lupus 25(9):1028-39

Leeman, J; Crandell, JL; Lee, A; Bai, J; Sandelowski, M; Knafl, K (2016) Family Functioning and the Well-Being of Children With Chronic Conditions: A Meta-Analysis Research in Nursing \& Health, 39, 229-243

Lambert, V and Keogh, D; (2015) Striving to Live a Normal Life: A Review of Children and Young People's Experience of Feeling Different when Living with a Long Term Condition Journal of Pediatric Nursing 30, 63-77

Lum, C. E. Wakefield, B. Donnan, M. A. Burns, J. E. Fardell and G. M. Marshall (2017) Understanding the school experiences of children and adolescents with serious chronic illness: a systematic metareview Child: care, health and development 43(5):645-662

MacLean A and Harden J. (2014) Reflections on researching with children using 'family group interviews' as part of a qualitative longitudinal study. International Journal of Child Youth and Family Studies 5:649-665.

Mowry, EM; Julian,L; Im-Wang, S; Chabas, D; Galvin, AJ; Strober, JB; Waubant, E. (2010) HealthRelated Quality of Life is Reduced in Pediatric Multiple Sclerosis. Pediatric Neurology 43 (2) 97-102

Monaghan, L and Gabe, J (2015) Chronic illness as biographical contingency? Young people's experiences of asthma Sociology of Health \& IIIness 37 (8) 1236-1253

Monaghan, L and Gabe, J (2016) Embodying health identities: A study of young people with asthma Social Science \& Medicine $1601 \mathrm{e} 8$

Nylander, C., Seidel, C., \& Tindberg, Y. (2014). The triply troubled teenager - Chronic conditions associated with fewer protective factors and clustered risk behaviours. Acta Paediatrica, 103, 194200.

Pinquart, $M$ and Shen, $Y$ (2010) Depressive Symptoms in Children and Adolescents with Chronic Physical Illness: An Updated Meta-Analysis. Journal of Pediatric Psychology. 36(4) 375-384

Pini, S; Gardner, P; Hugh-Jones, S (2012) What effect does a cancer diagnosis have on the educational engagement and school life of teenagers? A systematic review Psycho-Oncology 21: 685-694

Pini, S; Gardner, P; Hugh-Jones, S (2016) How teenagers continue school after a diagnosis of cancer: experiences of young people and recommendations for practice Future Oncology 12 (24) 2785-2800

Pendley, JS; Kasmen, L; Miller, DL; Donze, J; Swenson, C; Reeves, G. (2002) Peer and Family Support in Children and Adolescents With Type 1 Diabetes Journal of Pediatric Psychology, 27 (5) 429-438

Saunders, B (2017) 'It seems like you're going around in circles': recurrent biographical disruption constructed through the past, present and anticipated future in the narratives of young adults with inflammatory bowel disease Sociology of Health \& IIIness. 39(5):726-740 
Secor-Turner, M; Scal, P; Garwick, A; Horvath, K; Wells, CK (2011) Living With Juvenile Arthritis: Adolescents' Challenges and Experiences Journal of Pediatric Health Care 25 (5) 302-17

Thannhauser JE. (2009) Grief-peer dynamics: understanding experiences with pediatric multiple sclerosis. Qualitative Health Research 19: 766-777.

Thannhauser JE, Mah JK and Metz LM.(2009) Adherence of adolescents to multiple sclerosis disease-modifying therapy. Pediatric Neurology 41: 119-123.

Taylor, RM; Gibson, F; Franck, LS (2008) The experience of living with a chronic illness during adolescence: a critical review of the literature Journal of Clinical Nursing, 17, 3083-3091

Tong,A; Jones,J; Craig, JC; Singh-Grewal, D (2012) Children's Experiences of Living With Juvenile Idiopathic Arthritis: A Thematic Synthesis of Qualitative Studies Arthritis Care \& Research. 64 (9) 1392-1404

Toussaint-Duyster, LC; Wong, YY; Van der Cammen-van Zijp, M; Van Pelt-Gravesteijn, D; CatsmanBerrevoets, C. (2018) Fatigue and physical functioning in children with multiple sclerosis and acute disseminated encephalomyelitis Multiple Sclerosis 24(7):982-990.

Venning, A.; Eliott, J; Wilson, A; Kettler, L. (2008) Understanding young peoples' experience of chronic illness: a systematic review International Journal of Evidence-Based Healthcare 6: 321-336

Young, B; Dixon-Woods, M. Windridge, KC; Heney, D. (2003) Managing communication with young people who have a potentially life threatening chronic illness: qualitative study of patients and parents British Medical Journal 326 :305

Wiener, L; Mellins,CA; Marhefka, S; Battles, HB (2007) Disclosure of an HIV diagnosis to Children: History, Current Research, and Future Directions Journal of Developmental and Behavioural Pediatrics. 28(2): 155-166.

Williams, C (2000) Doing health, doing gender: teenagers, diabetes and asthma Social Science \& Medicine 50 387-396

Williams, B., Corlett, J., Dowell, J., Coyle, J., Mukhopadhyay, S. (2009) 'I've never not had it so I don't really know what it's like not to': nondifference and biographical disruption among children and young people with cystic fibrosis, Qualitative Health Research, 19 (10) 1443-55.

Williams, S.J. (2000) Chronic illness as biographical disruption or biographical disruption as chronic illness?, Reflections on a core concept, Sociology of Health \& IIIness, 22 (1), 40-67. 
Table 1: Characteristics of Participants $(n=21)$

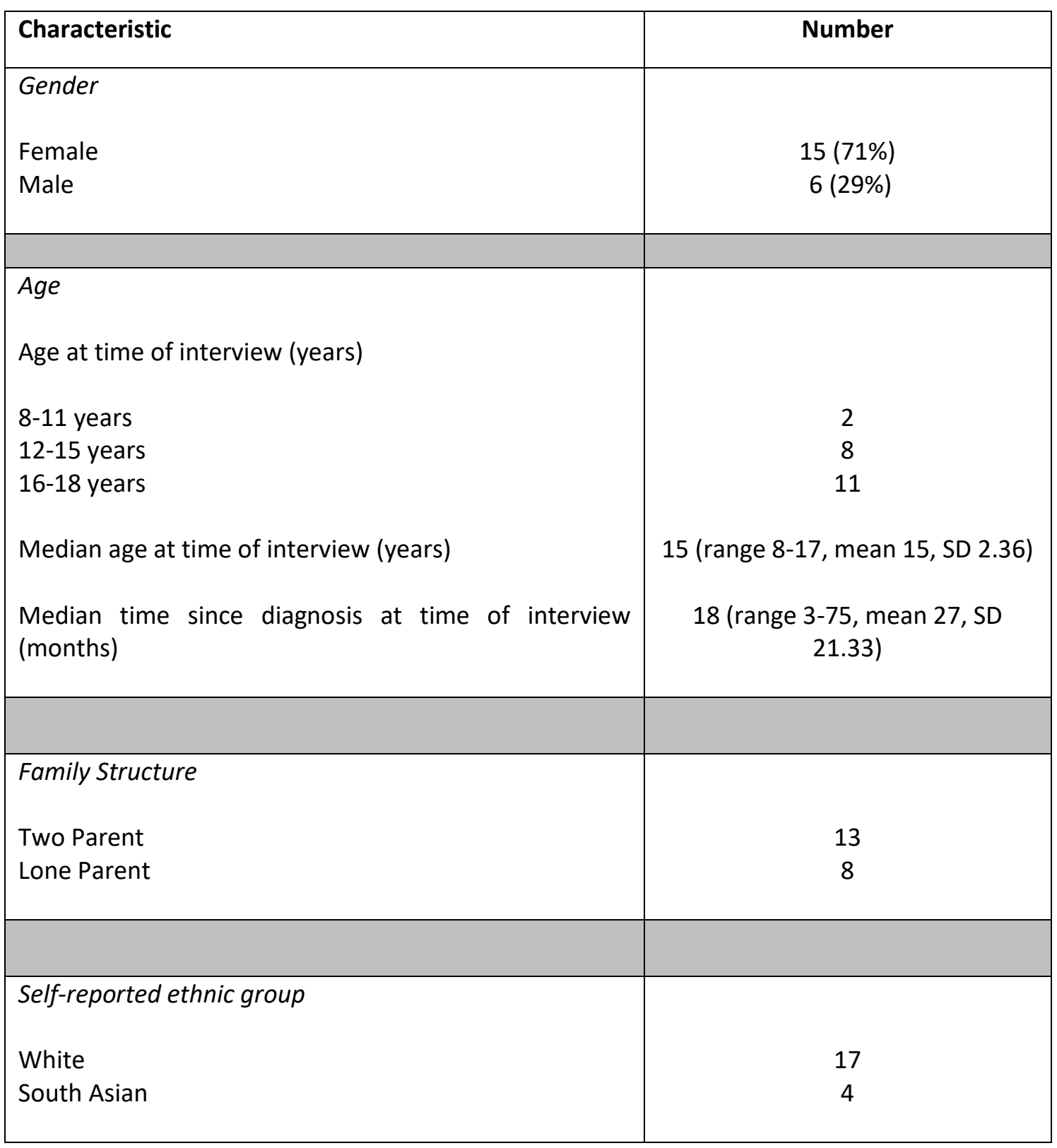

Table 2: Interview Structure $(n=21)$

\begin{tabular}{|l|c|}
\hline Composition & Number \\
\hline Young person and one parent & 14 \\
Young person and mother & 12 \\
Young person and father & 2 \\
Young person and two parents & 6 \\
Young person only & 3 \\
\hline
\end{tabular}




\section{Figure 1: Interview Topic Guide}

The past

- Life before diagnosis and events leading up to diagnosis

- Diagnosis experience

- Support and services received during/after diagnosis.

\section{The present}

- Daily life and the care and support s/he currently needs.

$>$ Relapses/remissions - experience and impact

$>$ School/college

$>$ Social life - social activities and experiences

$>$ Likes and dislikes

$>$ Relationships with parents/siblings/friends/carers and others.

- Perception of the impact of MS on parents and other family members (e.g. siblings).

- Perception of needs

$>$ Preferences for support

$>$ Barriers to needs being met

- Sources of support - experiences and views.

$>$ Use of informal support networks (family/friends/support groups).

Health care services

Teachers and school

$>$ Social workers

- Involvement in decision-making

The future

- Plans and aspirations for the future

- Anticipated future support needs. 
Figure 2: Reflexivity on Data Collection

How did I present myself during the interview and what did I disclose about myself (e.g parent role, level of knowledge about MS)?

How successful was I in establishing rapport with the young person?

Were there any non-verbal signals during the interview to indicate that particular issues were problematic?

How engaged was the young person in the interview? Did I check out that they wanted to continue talking to me?

How far did they share their personal experiences with me?

Were there any questions that they did not respond to or changed the subject?

How well did I listen during the interview and follow up cues?

Did I use the appropriate terminology and language? Did they understand what I was asking?

Did I give young people time to reflect before answering?

Was I surprised by any responses? Could I have demonstrated this?

Did they ask me any questions? What were these about?

Did they introduce topics into the interview? Did their concerns emerge during the interview?

If parents were present - what did they say and do during the interview? How did the young person respond to this?

How might the environment have influenced the interview?

What did I think/feel during and after the interview? 


\section{ACKNOWLEDGEMENTS}

The researchers would like to thank the young people who took part in the study for sharing their views with us and the clinicians at the NHS trusts, the MS Society, MS-UK, shift.MS and the UK Multiple Sclerosis Specialist Nurse Association for providing valuable help with recruitment. We would particularly like to thank Dr Kathy Hawley and the study advisory group for their advice throughout the project. The researchers acknowledge the support of the National Institute for Health Research, through the Clinical Research Network. This study was funded by the Multiple Sclerosis Society in the UK. 